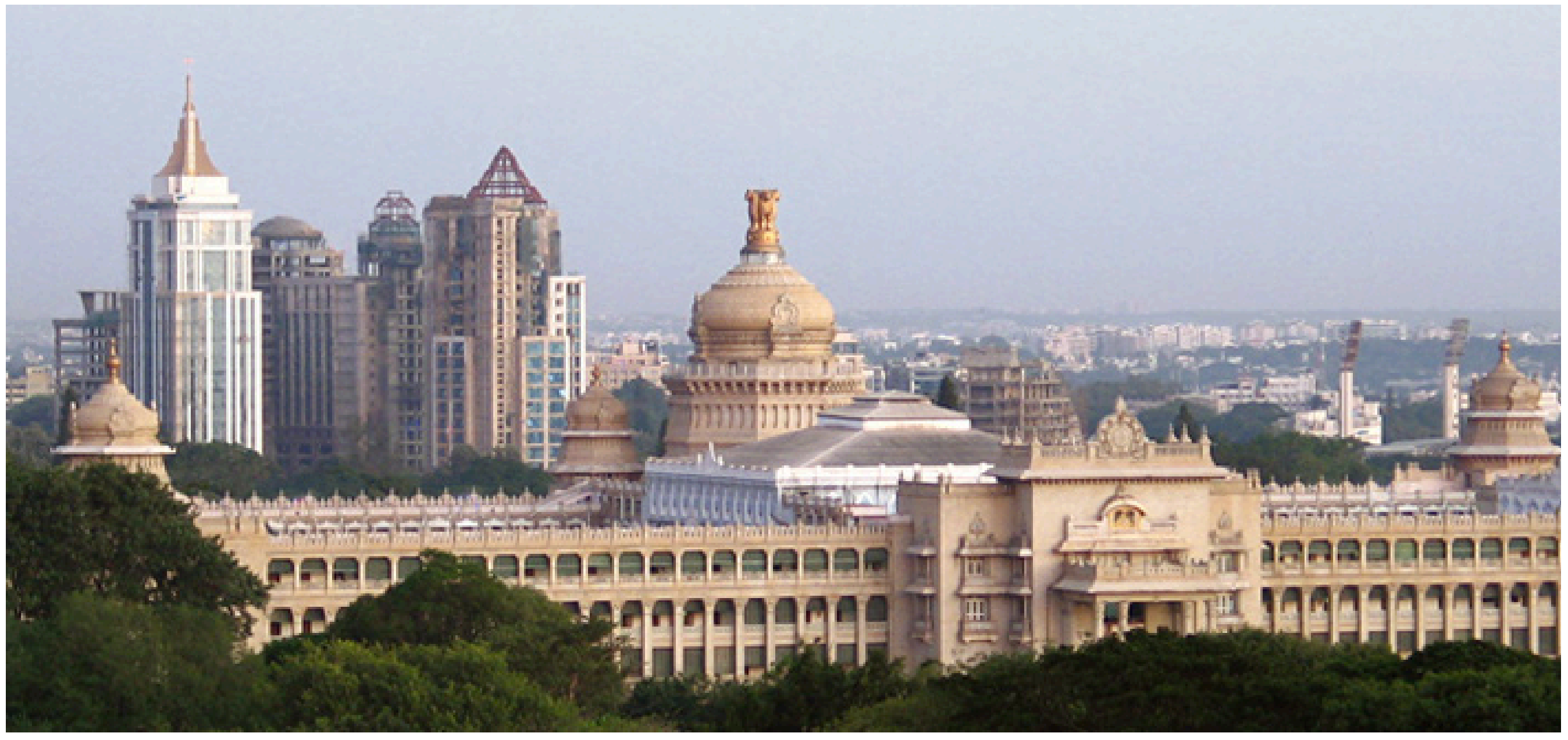

B a n g allore India

Sustainable Cities Initiative City Report

January 2014

Authors | Aromar Revi, Garima Jain, Neha Sami Indian Institute for Human Settlements, India 


\begin{tabular}{|c|c|c|c|c|c|}
\hline \multicolumn{6}{|c|}{ Bangalore City Snap Shot } \\
\hline \multicolumn{2}{|c|}{ Description } & Unit & 1990 & 2001 & 2011 \\
\hline \multicolumn{6}{|l|}{ People } \\
\hline \multicolumn{2}{|c|}{ Population } & million & 3.3 & 4.3 & 8.5 \\
\hline \multicolumn{2}{|c|}{ Decadal Population Growth } & percent & 30 & $31 \%$ & $98 \%$ \\
\hline \multicolumn{2}{|c|}{ Average Literacy } & percent & $41 \%$ & $75 \%$ & $80 \%$ \\
\hline \multicolumn{2}{|c|}{ Sex Ratio } & females per 1000 males & 913 & 918 & 914 \\
\hline \multicolumn{2}{|c|}{ Mean Life Expectancy at Birth } & years & 63 & 66 & 67 \\
\hline \multicolumn{6}{|c|}{ Economy } \\
\hline \multicolumn{2}{|c|}{ City GDP } & US\$ billion PPP & 0.1 & 5 & 10 \\
\hline \multicolumn{2}{|c|}{ City Per Capita Income } & US\$PPP/year & 106 & 235 & 531 \\
\hline \multicolumn{2}{|c|}{ Proportion of National GDP } & US\$PPP/year & $0.02 \%$ & $0.4 \%$ & $0.4 \%$ \\
\hline \multicolumn{6}{|c|}{ Area and Land Use } \\
\hline \multicolumn{2}{|c|}{ Area } & sq. km. & 276 & 226 & 741 \\
\hline \multicolumn{2}{|c|}{ Population Density } & people / sq. km. & 11,948 & 19,065 & 11,371 \\
\hline \multicolumn{2}{|c|}{ Proportion of State Population } & per cent & $7 \%$ & $11 \%$ & $14 \%$ \\
\hline \multicolumn{2}{|c|}{ Land Use } & & & & \\
\hline & Residential & percent & & & $43 \%$ \\
\hline & Business/Industry & percent & & & $7 \%$ \\
\hline & Transport/Roads & percent & & & $21 \%$ \\
\hline & Green Cover & percent & & & $22 \%$ \\
\hline & Others & percent & & & $8 \%$ \\
\hline
\end{tabular}

\section{About the City}

Bangalore is the primate city in Karnataka, a state in India, contributing almost 34 per cent to the state's GDP. While it has a long history of manufacturing (especially textile), the last few decades have seen it grow into a global center for information technology and related services with several domestic and international corporations such as Wipro, Infosys, Microsoft, and IBM locating offices here.

However, the benefits of Bangalore's growth have not been equally distributed, with about 43 per cent of the city's population living in multi-dimensional poverty. Moreover, the city's physical footprint has increased by over 100 per cent in the last decade, although the city continues to have a low-density core: the built-up area has increased at the cost of the city's vegetation and water resources. In particular, the growth on the city's peripheries (towards the north and the south-west) is putting an increasing amount of pressure on Bangalore's natural and economic resources. Bangalore faces considerable risks if it were to continue on its current development pathway.

To continue to leverage its knowledge-based economy, the city needs to address multiple challenges across a range of sectors. Based on early discussions and secondary reviews, issues concerning water management have emerged as among the most critical, particularly the question of reducing access to good quality and reliable water. Sanitation and sewerage infrastructure in Bangalore is also in disrepair. The city depends to a large extent on increasingly contaminated groundwater for its water supply. Inadequate management of water supply and sanitation poses environmental and health risks for the entire city, especially for low-income and other vulnerable populations like women, children, and the elderly. Other areas of concern that have emerged include energy, which is also linked to the dwindling water supply, and transportation.

Bangalore's physical footprint has increased by over a 100 per cent from 1992 to 2009 with a 134 per cent increase in built up area, accompanied by a sharp decline in water bodies and natural vegetation (Census of India, 2011; Indian Institute for Human Settlements (IIHS), 2009; Ramachandra and Kumar, 2009). Bangalore's population has registered a growth of over 40 per cent in the last decade to reach an estimated 8.5 million in 2011. However, Bangalore has a low density core, and is driven by preferential peripheral investments, the limited ability to change designated land-use in the core, greater personal mobility and motorisation as middle class disposable incomes rise and significant speculative development, new development is typically taking place away from the city core, leading to extensive sprawl. The densification of the core is a very complex issue particularly because it will involve significant reform of a messy land market, as well as integrated mass transit development and a massive investment in upgrading core trunk infrastructure to cope with increased densities and loading. While this is critical for Bangalore to grow sustainably, it is an issue that can only be dealt with in the long-term.

At the same time, Bangalore is facing a wide range of risks to its future growth and prosperity from issues such as water scarcity, climate change, damage to important natural habitats, and growing traffic congestion associated with private vehicle use. Unchecked, these issues could place a significant break on future economic growth and improvements on the quality of life of its residents. However, Bangalore has an opportunity to address these issues as part of its growth aspirations by looking at actions it can take now to develop along a sustainable trajectory. 
Urban SDG Target A - Eliminate extreme urban poverty, expand employment and productivity, and raise living standards, especially in slums and informal settlements

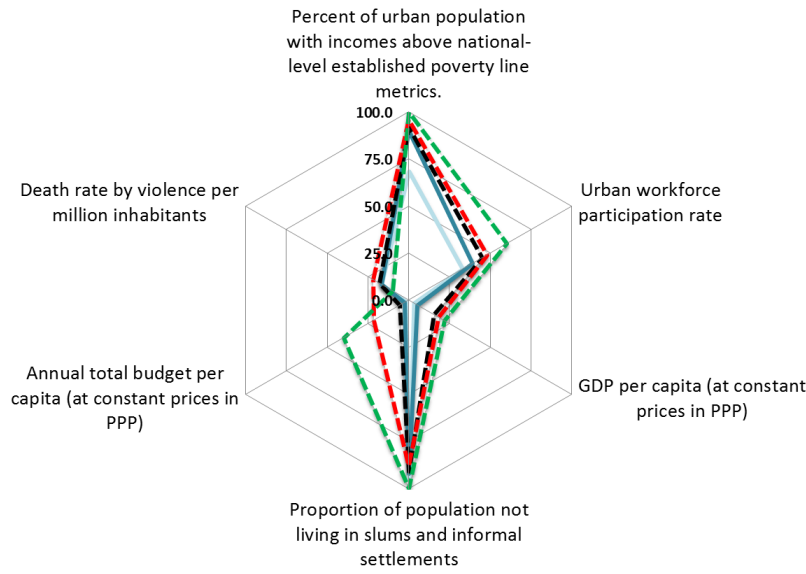

1. Percent of urban population with incomes above national-leve established poverty line metrics. The data has been derived either from the works of Rao, K. N. (2005). Poverty in India: Global and Regiona Dimensions: Deep and Deep Publications, or from the Ministry of Consumer Affairs, Food and Public Distribution. It is measured with respect to the national poverty line, even though poverty line itself is not a measure of the multi-dimensional poverty that persists.

2. Urban workforce participation rate. Data is from the Census of India 1991, 2001 and 2011.

3. GDP per capita (at constant prices in PPP). District Domestic Product Per Capita at Current Prices for Bangalore Urban District is available for 1999 till 2005. Rest are projections made on the basis of them. http://planningcommission.nic.in/plans/stateplan/index. php?state=ssphdbody.htm

4. Proportion of population not living in slums and informal settlements. This data is from the Census of India.

5. Annual total budget per capita (at constant prices in PPP). Data is derived from Sita Sekhar and Smita Bidarkar, Municipal Budgets in India: Comparison across Five Cities, EPW 1999, as well as City's Municipal Budgets.

6. Death rate by violence per million inhabitants. This shows reported data for murder, attemt to murder, rape, kidnapping and abduction, dacoity, robbery, Burglary and Theft, as a part of cases reported under the Indian Penal Code (IPC) . This number may be severely under reported. Death due to political violence, etc. is not captured in this. 1991 AntiTamil violence in Karnataka had some additional repurcussions, but the numbers are not documented. http://ncrb.nic.in/CD-CII2012/Additional Tables_CII_2012/Additional\%20table\%202012/DistrictWise\%20IPC\%20 cases\%20during\%202001-2012.pdf
Urban SDG Target B - Ensure universal access to a secure and affordable built environment and basic services: housing, water, sanitation and waste management; low-carbon energy and transportation; and communication.

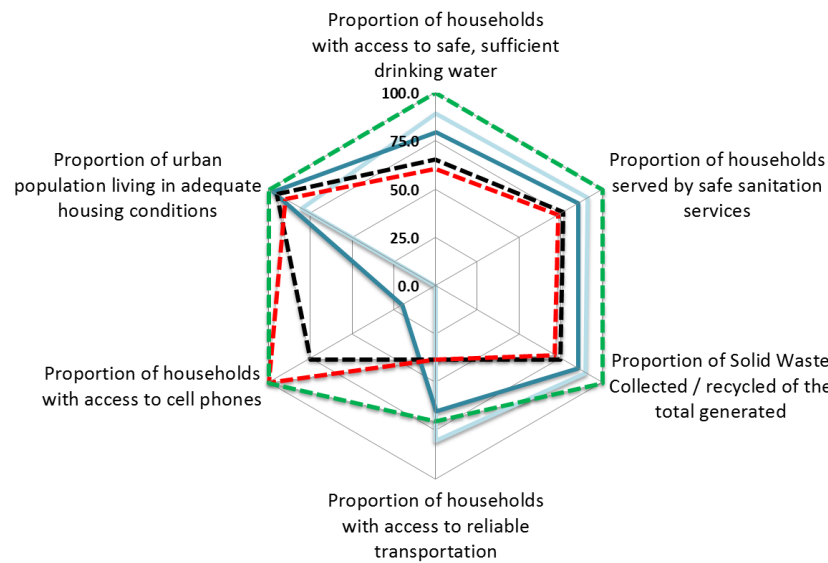

1. Proportion of households with access to safe, sufficient drinkin water. District Data is from the Census of India (http://www.censusindia. gov.in/2011census/hlo/District_Tables/Distt_table/29/HH22062900CRCD.pdf) and City data from the Bengaluru Portrait by Centre for Science and Environment, 2012.

2. Proportion of households served by safe sanitation services. District Data is from the Census of India (http://www.censusindia.gov. in/2011census/hlo/District_Tables/Distt_table/29/HH2808-2900DCRC. pdf) and City data from the Bengaluru Portrait by Centre for Science and Environment, 2012.

3. Proportion of solid waste collected / recycled of the total generated. This data is not collected at the city level in Bangalore, although some estimates are avilable for the year 2013 by B.Sudhakara Reddy and P. Balachandra ( http://www.igidr.ac.in/pdf/publication/WP-2013-008.pdf)

4. Proportion of households with access to reliable transportation. This data is not collected at the city level in Bangalore, although some estimates are avilable for the year 2013 in the Draft Bangalore Mobility Indicators (http://www.indiaenvironmentportal.org.in/files/Draft\%20 Bangalore\%20Mobility\%20Indicators\%202008.pdf)

5. Proportion of households with access to cell phones. 2011 Data from the Census of India (http://www.censusindia.gov.in/2011census/hlo/ District_Tables/Distt_table/29/HH4012-2900DCRC.pdf). Estimates are made for the year 2000 based on expert interviews. And since mobile phones made their entry in the country in 1996, 1990 data point is not applicable.

6. Proportion of urban population living in adequate housing conditions. Data is from the Census of India 2001 and 2011 (http://www. censusindia.gov.in/2011census/hlo/District_Tables/Distt_table/29/ HH0101-2900CRCD.pdf)
Urban SDG Target C - Ensure safe air quality \& water quality for all, and integrate reductions in greenhouse gas emissions, efficient land and resource use, and climate and disaster resilience into investments \& standards

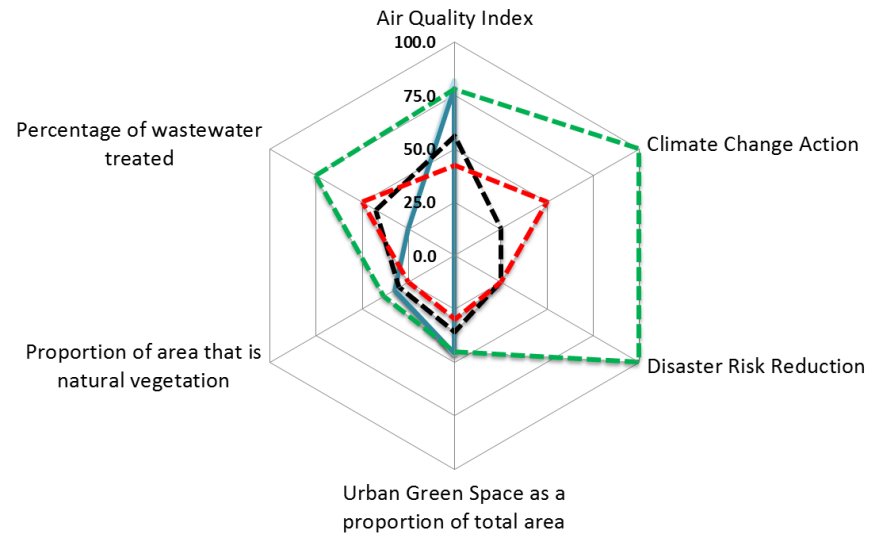

1. Air Quality Index. Using the Standards for Annual Mean

Concentration Range (micro gm / m3), Low = 100, Medium = 75, High $=$ 50 , Critical $=25$ are set for each of SO2, NO2, RSPM and SPM, and the averaged for a particular year. Data for these is available at the Centra Pollution Control Board, Ministry of Environmnet and Forests, Govt. of India.

2. Climate Change Action Index. The index is devised as follows: $25 \%$ if a CCA plan exists, $50 \%$ if there is a dedicated CCA authority, $75 \%$ othe departments have CCA integrated in their plans, $100 \%$ if dedicated funding is available at the city level for mitigation and adaptation

3. Disaster Risk Reduction Index. The index is devised as follows: $25 \%$ if a DRM plan exists, $50 \%$ if there is a dedicated DRM authority, $75 \%$ if early warning systems are available, $100 \%$ if dedicated funding is available at the city level.

4. Urban Green Space as a proportion of total area. Information is derived from - 'Greater Bangalore: Emerging Urban Heat Island', Ramachandra and Kumar, 2011

5. Proportion of area that is natural vegetation. Information is derived from - 'Graying, greening and fragmentation in the rapidly expanding Indian city of Bangalore', Harini Nagendraa,Suparsh Nagendrana, Somajita Paula, Sajid Pareetha , 2012.

6. Percentage of wastewater treated. Data is derived from the following sources:

2000 : N. Latha, N Deepa, B K Anand, K V Raju, H L Shashidhara, Wastewater Reuse in Megacities - Emerging Trends in Bangalore city 2010 : THE DECCAN BENGALURU - Bengaluru THE WATER-WASTE PORTRAIT

2015 : http://www.igidr.ac.in/pdf/publication/WP-2013-008.pdf 
In the last two decades, Bangalore has emerged as a global centre for 'new' service sector economies like information technology and biotechnology attracted partly by the numerous academic institutions and the skilled workforce they produce (H. S. Sudhira et al., 2007). Bangalore has the highest district income in the state, contributing approximately 33.5 per cent to Gross State Domestic Product (GSDP) at current prices (Directorate of Economics and Statistics, 2011) and is a magnet for investments and employment in Karnataka. In addition to new service sector industries, Bangalore is also a stronghold of the domestic textile industry and other light manufacturing. The benefits of this growth have not been spread equally across all socio-economic classes. The number of informal settlements in the city have grown from approximately 540 in 2007 to about 640 in 2011 (Karnataka Slum Clearance Board (KSCB), 2011; H. S. Sudhira et al., 2007). While the 1950s to the 1980s had been characterized by public sector investment, the 1990s saw the growth of the private sector, particularly information technology (IT) and related industries. To entice businesses, the state government of Karnataka is offering them several land and tax incentives in addition to building mega-infrastructure projects like elevated roads, a new metro, a new airport, and setting up special economic zones (SEZs). This rapid growth of new economic sectors in Bangalore has considerably boosted the real estate industry, locally and regionally (Benjamin, 2006; Nair, 2005).
Actual water availability within the city of Bangalore is function of rainfall within the Cauvery River catchment (fed predominantly by monsoon rains); pipeline systems linked with water storage and replenishable groundwater resources within the city boundary. The Karnataka State Level Climate Change Plan estimates that total rainfall could reduce by as much as $10 \%-20 \%$ by 2050 . The combination of increasing demand for water resources, poor water distribution infrastructure, and contamination of existing supplies could constrain the ability of Bangalore to grow and prosper in the future as demand in the city and wider region continues to grow. Development is already constrained in areas of the city without a piped network where there is only limited access to ground water. The lack of latrine facilities, with many households lacking access and high fees being paid for public facilities, have forced citizens to resort to open areas, contributing to the spread of diseases (e.g. worms, diarrhoea, cholera and typhoid) (Solomon, 2000). Similar issues exist fo waste collection, which encompasses $80 \%$ of the city's waste, but in slums is often not removed at all, unless inhabitants pay municipal representatives directly. Formal measurements tend to overlook the role of "human infrastructure"; in Bangalore an estimated 10 '000 street sweepers ("pourakarmikas") with minimum wages and rough working conditions are in charge of cleaning streets and garbage dumps (CIVIC 2008).
Bangalore's growth dynamics point towards growing energy use coupled with an inadequate public transport system, and increasing water scarcity. Large sections of the city are also exposed to specific hazards such as urban floods and water scarcity because of rapid and unplanned urbanisation. Air pollution and the outward growth of the city are contributing to an urban heat island effect, which has been noted to result in local temperature variations and irregular rain showers Ramachandra and Kumar, 2010; Ramachandra and Kumar, 2009). This urban heat island effect is exacerbated by reducing tree cover and increasing built-up area, and has serious health implications for the local population. Most of these hazards will be exacerbated by projected climate change impacts for the region, such as extreme heat days, rise in mean temperature, heavy precipitation events or storms, and periods of low rainfall. Increasing densities and growing land prices leave people with limited choice and many of them are forced to live in more exposed areas or low lying areas, with minimal access to basic services and resources, thereby increasing their own vulnerabilities. The low awareness of the risks increases the exposure to them. Children below the age of 6 , elderly, women and the disabled, are often the most vulnerable. Their access to financial institutions, public programmes and social protection is often limited, resulting in low resilience to shocks. 